\title{
Formation of the hamster zona pellucida in relation to ovarian differentiation and follicular growth*
}

\author{
M. C. Léveillé†, K. D. Roberts, S. Chevalier, A. Chapdelaine and G. Bleau \\ Departments of Obstetrics and Gynecology, Biochemistry and Medicine, University of Montreal and \\ Maisonneuve-Rosemont Research Center, Montreal, Quebec, Canada HIT 2M4
}

\begin{abstract}
Summary. Using an immunofluorescence technique on ovarian sections, zonaimmunoreactive components were detected in the cytoplasm of the oocyte from the beginning of its growth, when it is surrounded by only a thin squamous follicular cell layer, up to the end of its growth. In parallel with oocyte growth, the staining intensity decreased in the ooplasm. No staining was observed in the cytoplasm of the granulosa cells during normal follicular development in adult cyclic females. However, staining of the granulosa cells was observed at some stages of follicular development in immature females. This staining was especially evident in the ovaries of immature females (22 or 26 days old) stimulated with PMSG. In addition, the staining of the granulosa cells was consistently observed in ovaries showing an abnormal histology. Increased staining of the zona at its outer and inner regions could be distinguished in normal follicles, but when staining occurred on the granulosa cells no such pattern was observed over the zona matrix. These studies indicate that the oocyte itself but not the granulosa cells elaborates the native immunogenic material of the zona pellucida. The administration of PMSG at particular stages of ovarian differentiation interferes with follicular development leading to an abnormal extracellular assembly of the zona and its degradation (phagocytosis) by the surrounding granulosa cells.
\end{abstract}

\section{Introduction}

In the mammalian ovary, the zona pellucida appears as an extracellular glycoprotein structure that encloses the oocyte. After ovulation, the zona pellucida surrounds the egg until the time of implantation of the embryo in most species. Under the scanning electron microscope, it appears as a complex fibrous network interspersed with numerous pores (Dudkiewicz \& Williams, 1977). As its assembly proceeds, the zona pellucida acquires specific molecular domains each bearing important biological functions. Thus, the zona pellucida confers to the egg its species-specific binding affinity for spermatozoa and later it provides the major block to post-fertilization polyspermy (Wassarman \& Bleil, 1982). The zona also appears to protect the growing embryo as it passes down the oviduct (Mintz, 1962; Modlinski, 1970).

Although the morphological, biochemical and immunochemical properties of the zona pellucida of many species have been described extensively (see review by Dunbar, 1983), few studies have been carried out to correlate the synthesis and extracellular assembly of the zona with oocyte growth and follicular development. Using ultrastructural and histochemical criteria, a zona pellucida-like material has been reported within as well as around the granulosa cells and this led to

*Reprint requests to Dr G. Bleau, Maisonneuve-Rosemont Research Center, 5415 Blvd de L'Assomption, Montreal, Quebec, Canada HIT 2M4.

$†$ Present address: MRC Group in Reproductive Biology, University of Western Ontario, University Hospital, 339

Windemere Road, London, Ontario, Canada N6A 5A5. 
the suggestion that the granulosa cells may be primarily responsible for the production of the zona (Chiquoine, 1960; Tesoriero, 1984). On the other hand, Kang (1974) described the formation of an amorphous material similar to the zona in the vesicles of Golgi complexes in the cytoplasm of the oocyte and so proposed that the oocyte is the site of synthesis of zona proteins. Zamboni \& Upadhyay (1983) found zona material around ectopic oocytes from postnatal animals. Autoradiography after $\left[{ }^{3} \mathrm{H}\right]$ fucose administration also suggested that the oocyte may play a role in the synthesis of the zona pellucida (Haddad \& Nagai, 1977; Fléchon et al., 1984). Wassarman et al. (1984) have established that glycoprotein components of the mouse zona can be synthesized by denuded mouse oocytes grown in vitro and precursors for the zona proteins were found in these oocytes after in-vitro incubation with $\left[{ }^{35} \mathrm{~S}\right]$ methionine or $\left[{ }^{3} \mathrm{H}\right]$ fucose. However, since extracellular regulatory mechanisms are lost during in-vitro labelling studies, this type of experiment did not allow the study of the control of the extracellular assembly of the zona during oocyte growth and follicular development. Our approach was to use immunohistochemistry to follow the evolution of zona assembly during normal and abnormal follicular development.

Up to the present time, only one such study has been carried out: Wolgemuth et al. (1984) showed that the assembly of the zona pellucida in the sexually mature rabbit is complex and may involve both the oocyte and the granulosa cells at certain stages of growth and maturation.

\section{Materials and Methods}

\section{Animals}

A total of 62 immature or adult (42 days of age) female golden hamsters (Mesocricetus auratus; Charles River Inc., St-Constant, Quebec, Canada) between 3 days and 4 months of age were used. Animals were maintained under a constant temperature of $20^{\circ} \mathrm{C}$ on a $14 \mathrm{~h}$ light:10 h dark lighting schedule (lights on at $06: 00 \mathrm{~h}$ ) with free access to rodent chow pellets and tap water. Immature females were obtained through breeding in our laboratory. Day 1 of pregnancy was identified as the morning when spermatozoa were recovered from the vagina. Pregnant females were caged separately before the birth of the young. Males and females were separated at the time of weaning (2l days) and kept in groups of 10 animals or fewer per cage.

Of the 62 females, 23 were injected (i.p.) with 10, 20 or 30 i.u. PMSG (Equinex: Ayerst Laboratories, Montreal, Quebec, Canada) at $16,22,26$ or 31 days of age and were killed $24-96 \mathrm{~h}$ later. One adult female was treated with 25 i.u. PMSG followed by 25 i.u. hCG (A.P.L., Ayerst) at $72 \mathrm{~h}$ and killed $17 \mathrm{~h}$ later: stimulation of ovarian follicular development and superovulation in adult females occur at these doses (Greenwald, 1962).

\section{Preparation of tissues for immunohistochemical localization}

Experiments were performed on ovaries and on control tissues including the spleen, liver, gut and lung. The animals were killed by cervical dislocation and tissues were excised and rapidly placed in cold neutral buffered formol (Biopharm, Montreal, Quebec, Canada). The specimens were cut into 10 to $200 \mathrm{~mm}^{3}$ pieces and kept in the fixative for $24 \mathrm{~h}$ at $4^{\circ} \mathrm{C}$. They were then dehydrated and processed for embedding in paraffix wax using an automatic circulation system (Shandon Southern Apparatus, John's Scientific, Montreal, Quebec, Canada). Paraffin wax sections ( $5 \mu \mathrm{m})$ were mounted onto gelatinized glass slides. A total of 120 sections were cut from each paraffin wax block (each female) and 20 serial sections were taken from 6 different depths inside a block. Two adjacent sections in each group of 20 sections were stained with haematoxylin, phloxine and safranine (H.P.S.) to verify tissue integrity and to aid in the selection of those sections to be used for immunohistochemistry. For each female, immunohistochemistry was done on $10-30$ sections.

\section{Preparation of the antiserum}

A male white rabbit was immunized with 1000 heat-solubilized zonae pellucidae obtained from hamster oviducal eggs emulsified in complete Freund's complete adjuvant (Bousquet et al., 1981). The first injection was administered at 15 intradermal sites, booster injections of the same amount of zona material in Freund's incomplete adjuvant were done at intervals of 7 to 20 days. The maximum titre, as tested by an indirect immunofluorescent assay on hamster ovulated eggs, was 1 in 1024 after the eight injections. The specificity of the antiserum was tested by absorption and indirect immunofluorescence (Sacco, 1977); it did not react with control tissues such as liver, brain, kidney, adrenal, testis and erythrocytes. Control animals were given complete Freund's adjuvant alone. 


\section{Indirect immunofluorescence}

Tissue sections on the slides were deparaffinized in toluene, rehydrated from absolute ethanol to $50 \%$ ethanol and soaked for $10 \mathrm{~min}$ in twice-distilled water. The sections were then covered with the diluted anti-zona serum or with equivalent dilutions of control serum. After an incubation of $1 \mathrm{~h}$ in a moist chamber at $23^{\circ} \mathrm{C}$, the slides were soaked in phosphate-buffered saline (PBS, $0.01 \mathrm{M}$-phosphate, $0.15 \mathrm{M}-\mathrm{NaCl}, \mathrm{pH} \mathrm{7.4)}$ with gentle stirring for 45 min. The slides were then returned to the moist chamber and covered with diluted fluorescein-conjugated goat anti-rabbit IgG (Miles Laboratories, Rexdale, Ontario, Canada). After an incubation of $1 \mathrm{~h}$ at $23^{\circ} \mathrm{C}$, the slides were washed as described above and the sections were mounted under coverslips in $90 \%$ glycerol-10\% PBS. From preliminary experiments, it was found that dilution ranges of $1 / 8$ to $1 / 32$ in PBS for the first antiserum and of $1 / 30$ to $1 / 100$ for the fluoresceinconjugated antibody provided optimal specific fluorescent staining. Control sera included normal rabbit sera, sera from rabbits immunized with complete Freund's adjuvant alone, anti-hamster zona serum absorbed with red blood cells or with homogenized hamster ovaries using a procedure similar to that described by Sacco \& Shivers (1973). Method controls included the use of PBS instead of the first antibody and the use of non-specific blocking agents such as albumin $(1 \% \mathrm{w} / \mathrm{v})$, gelatin $(1 \%-3 \% \mathrm{w} / \mathrm{v})$ or normal goat serum $(5 \% \mathrm{v} / \mathrm{v})$ in washings or antibody solutions or as a preincubation step to eliminate non-specific background staining (Petrusz et al., 1980). The slides were examined at $\times 10, \times 20, \times 40$ or $\times 100$ with an American Optical Microscope equipped with an epiillumination system. Colour photomicrographs were taken using Kodak Ektachrome 400 ASA slide film.

\section{Histology}

For each female, ovarian histology was documented from the H.P.S.-stained sections. Observations were made on an average of 6 sections at different depths of the ovary representing the structure of the entire organ. Follicular development and the appearance of the corpus luteum were recorded for each female.

Seven adult females were chosen for which at least 3 consecutive oestrous cycles had been recorded. These females were killed at defined periods of the cycle: metoestrus (Day 1), dioestrus I (Day 2), dioestrus II (Day 3) or oestrus (Day 4). These females served as models to classify the other adult females studied and for which no data regarding their cyclicity had been recorded. In addition, the follicular development in the ovaries of untreated females served as reference for comparison with changes produced by PMSG in adult or immature females.

\section{Results}

\section{Zona pellucida in follicles during normal development}

Sections of ovaries from 3-7-day-old females were examined for the presence of fluorescent staining in the oocytes at their earliest stage of differentiation. A positive staining was first observed on sections from 6-day-old hamsters. Although the ovarian follicular organization was difficult to ascertain in these ovaries (Fig. 1), the anti-zona serum recognized material localized within the cells which, based on their arrangement and large size (20-25 $\mu \mathrm{m}$ diam.), appeared to be the oocytes (Fig. 2). However, at 7 days of age, follicular development was clearly identified (Fig. 3); the fluorescence was distinctively predominant over the cytoplasm of the oocytes and began to be more intense close to their periphery (Fig. 4). No fluorescence was observed on sections of ovaries obtained from 3-, 4- or 5-day-old females.

The extracellular organization of the immunogenic zona components in relation to oocyte growth and follicular development was studied in females $>32$ days of age for which several stages of follicular development could be examined on a single section.

Figure 5 illustrates a 4-cell layer follicle enclosing a nearly full-grown oocyte surrounded by a well defined zona pellucida. At this stage of follicular development, only a weak immunoreactivity slightly above background was detected within the oocyte whereas an intense staining appeared over the zona pellucida (Fig. 6). A similar pattern was observed in those follicles that had reached the antral stage (Fig. 7). A heterogeneous pattern of staining was frequently observed over the zona and was characterized by a more intense staining at the inner and outer surfaces of the zona (Fig. 8). No staining above background on adjacent tissue was observed on follicular cells or in follicular fluid. However, an autofluorescence was observed on red blood cells (autofluorescence which was not eliminated by absorbing the sera on red blood cells). 

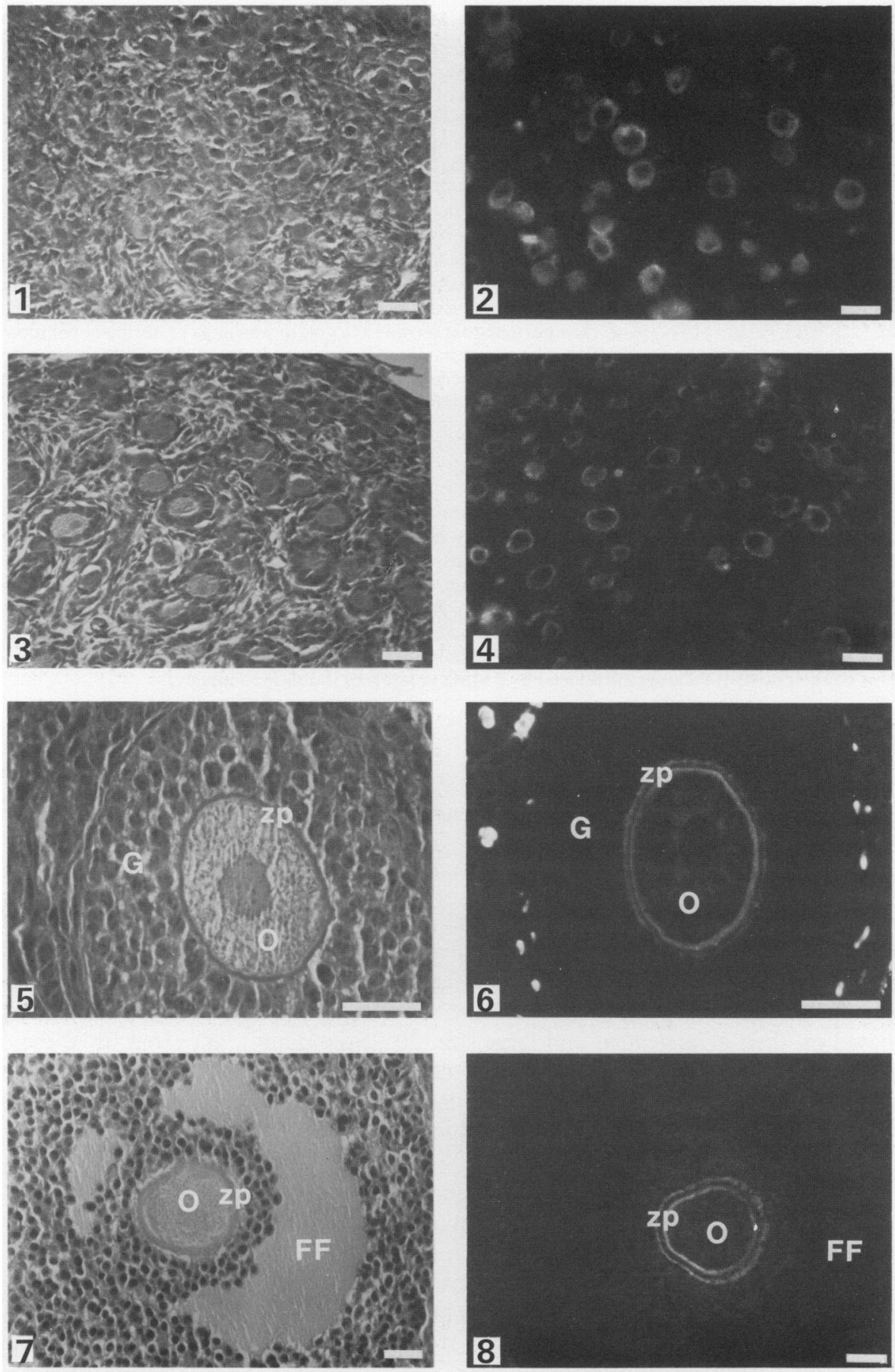

Figs 1-8. Localization of hamster zona immunoreactive components during ovarian follicular development: H.P.S.-stained sections of ovaries from hamsters of 6 days (Fig. 1), 7 days (Fig. 3), 32 days (Fig. 5) and 38 days (Fig. 7) and immunofluorescence on adjacent sections treated with anti-zona serum (Figs 2, 4, 6 \& 8). Figs 1 and 2: primordial follicies; Figs 3 and 4: onecell layer follicles; Figs 5 and 6: 4-cell layer follicle; Figs 7 and 8: antral follicle. Figs 2 and 4 were counterstained with Evans blue. FF: follicular fluid: G: granulosa; O: oocyte; zp: zona pellucida. Bars $=30 \mu \mathrm{m}$. 

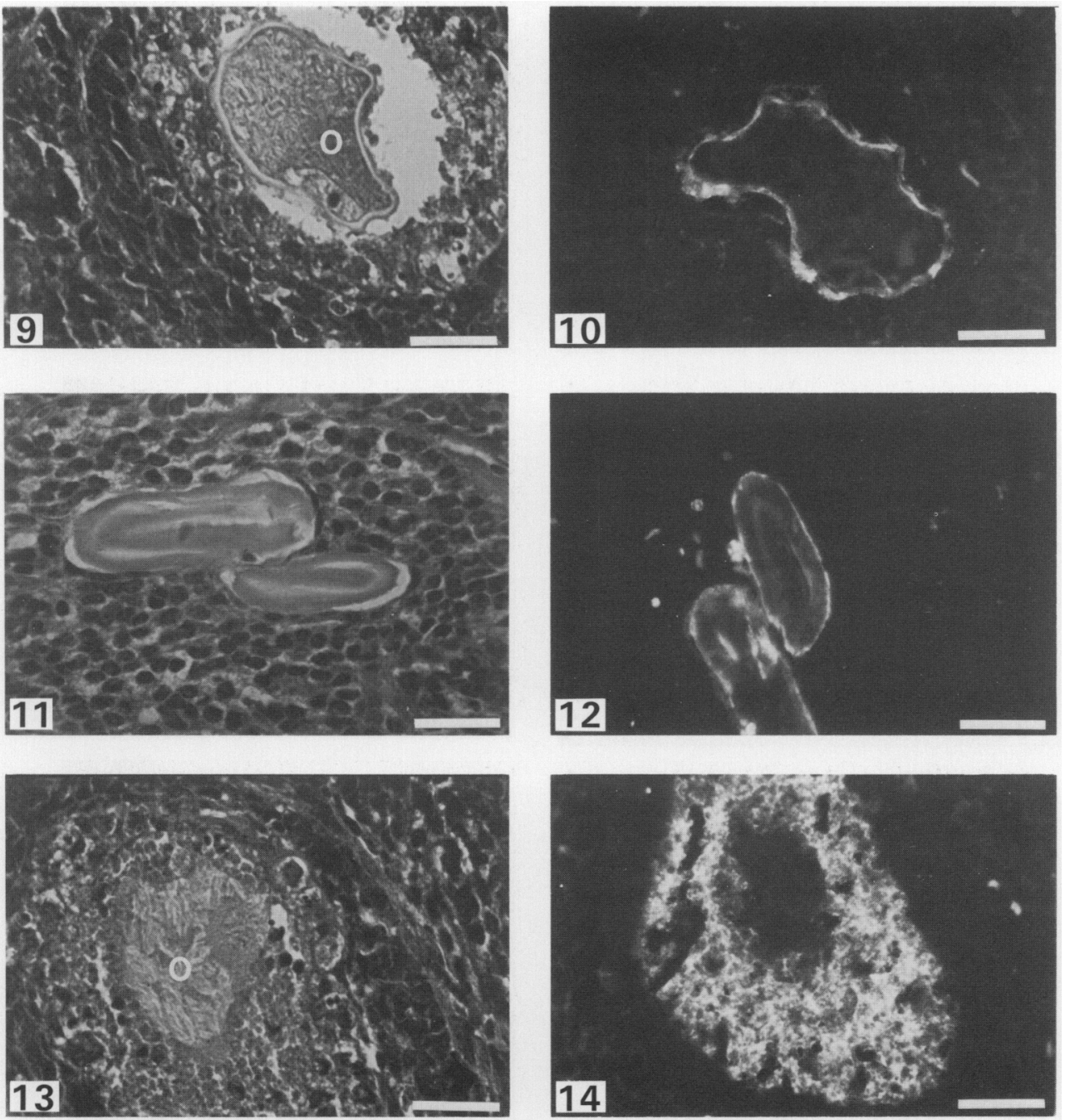

Figs 9-14. Localization of hamster zona immunoreactive components during atresia in preantral follicles: H.P.S.-stained sections (Figs 9, 11, 13) and immunofluorescence on adjacent sections treated with anti-zona serum (Figs 10,12,14). Figs 9 and 10: atretic follicle with a visible zona; Figs 11 and 12: shrivelled zonae; Figs 13 and 14: atretic follicle without any visible zona. O: oocyte. Bars $=30 \mu \mathrm{m}$.

\section{Zona pellucida of atretic follicles}

Alterations of the zona pellucida during atresia were detected by the indirect immunofluorescence technique. The zona pellucida was seen still present around the degenerated oocyte (Fig. 9) and the anti-zona serum still interacted with the distorted zona (Fig. 10). Distorted zonae, identified as the last remnants of these degenerated follicles, also reacted with the anti-zona serum (Figs 11 \& 12). In some cases, the zona was not visible (Fig. 13) and the fluorescent staining was spread over the entire follicle (Fig. 14). In some adult females, immunoreactive zona components were also observed in the granulosa cells. Staining was noted in 1-cell layer (Fig. 15) follicles as well as in follicles with many cell layers where the fluorescence was localized at the first layer of cells (Fig. 16). A similar 

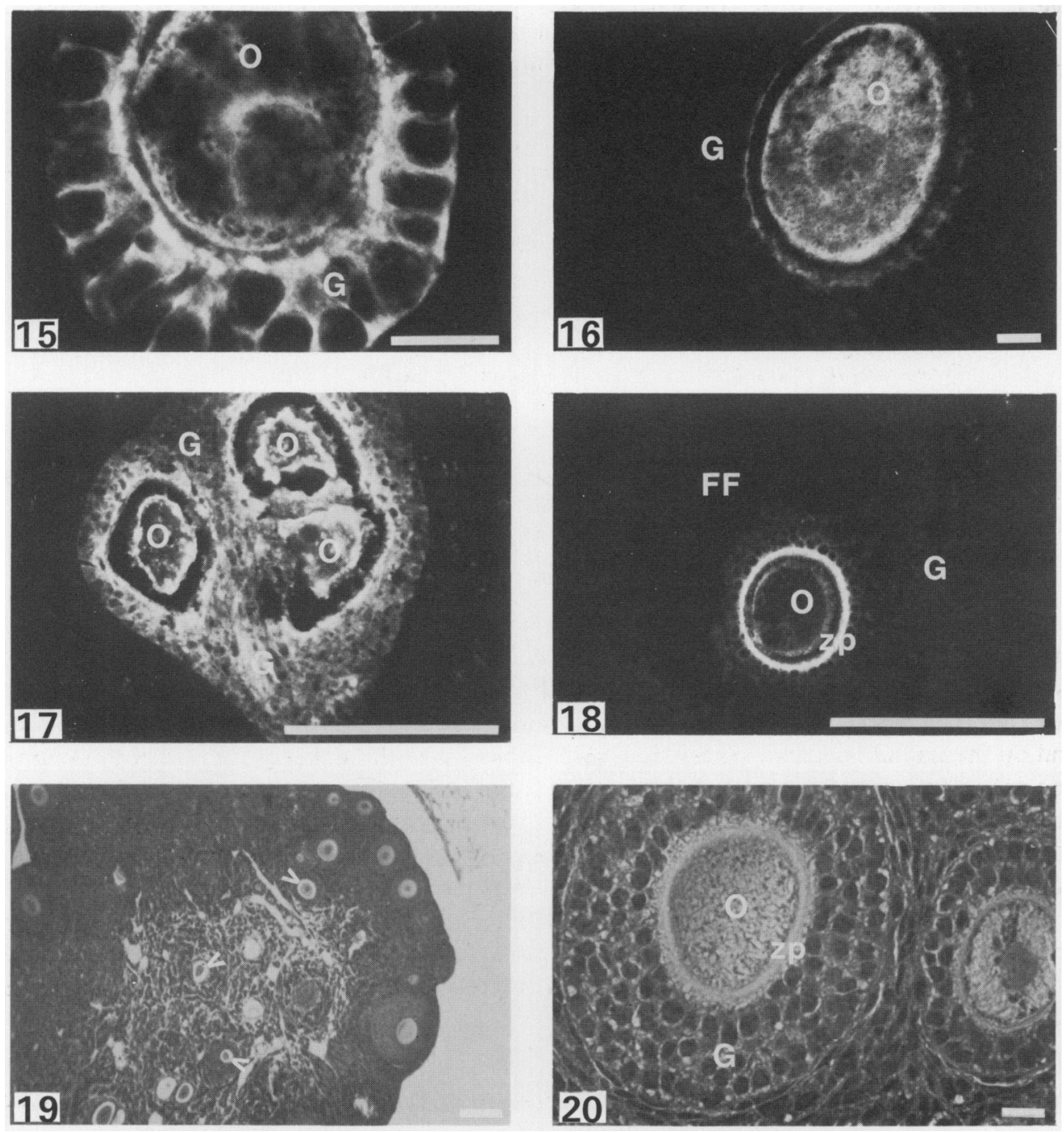

Figs 15-20. Immunoreactivity on the granulosa cells in sections of ovaries from adult females. Figs 15, 16, 17, 18: Immunofluorescence using anti-zona serum. Fig. 15: 1-cell follicle; Fig. 16: multiple-cell follicle; Fig. 17: atretic follicle with 3 oocytes; Fig. 18: antral follicle. Figs 19 and 20: H.P.S. staining on adjacent sections; note the condensed oocytes and the empty spaces (arrows) in Fig. 19. FF: follicular fluid; G: granulosa; n: nucleus; O: oocyte; zp: zona pellucida. Figs 15, 16, 20: bar $=15 \mu \mathrm{m}$; Figs 17, 18, 19: bar $=150 \mu \mathrm{m}$.

staining is also illustrated in an atretic follicle enclosing 3 degenerate oocytes (Fig. 17). In the latter follicle, zona remnants were detectable around the oocytes. No such staining was seen in antral follicles (Fig. 18).

Influence of the stage of the oestrous cycle

Since FSH and $\mathrm{LH}$ are implicated in the control of the proliferation and differentiation of granulosa cells and on certain occasions these cells appeared to contain zona immunogenic material, our immunohistochemical study was extended to take into account the stage of the 
Table 1. Summary of the immunoreactivity on the granulosa cells of adult hamsters using anti-zona serum

\begin{tabular}{llccc}
\hline $\begin{array}{l}\text { No. of } \\
\text { females }\end{array}$ & \multicolumn{1}{c}{$\begin{array}{c}\text { Stage of } \\
\text { the oestrous } \\
\text { cycle }\end{array}$} & $\begin{array}{c}\text { Follicular } \\
\text { development* }\end{array}$ & $\begin{array}{c}\text { Immunoreactivity } \\
\text { on granulosa } \\
\text { cells } \dagger\end{array}$ & $\begin{array}{c}\text { No. of } \\
\text { assays }\end{array}$ \\
\hline 3 & Oestrus & Antral (3); CL (2) & - & 6 \\
2 & Metoestrus & 8 G.L.; CL (2) & - & 6 \\
1 & Dioestrus I & Antral (2); CL (3) & - & 4 \\
1 & Dioestrus II & Antral (2); CL (3) & - & 3 \\
1 & Metoestrus (PMSG-hCG) & 5 G.L.; CL (6) & - & 2 \\
1 & Oestrus $\$$ & Antral (3); CL (2) & - & 4 \\
3 & Metoestrus $\ddagger$ & Antral (2); CL (1) & \pm & 4 \\
2 & Dioestrus pro-oestrus $\ddagger$ & Antral (2); CL (2) & - & 4 \\
2 & Dioestrus-pro-oestrus $\ddagger$ & & \pm \\
\hline
\end{tabular}

*Highest follicular development observed: number of layers of granulosa cells (G.L.), corpus luteum (CL); antral follicles include only stage 7 of the Pedersen classification (Pedersen \& Peters, 1968); in parentheses, highest number observed on one section.

$\dagger$ Fluorescence reactivity: - , all follicles observed were negative; \pm , some follicles were positive.

$\ddagger$ Estimated stage after comparison with cyclic females.

oestrous cycle. Indirect immunofluorescence using the anti-zona serum was applied on ovarian sections obtained from 16 adult females. Of these, 7 females were cyclic and one had been induced to superovulate. Staging of the other 8 females was based on ovarian histology (3 were in metoestrus, 1 in oestrus and 4 in dioestrus pro-oestrus). The levels of immunofluorescent staining found on the granulosa cells are summarized in Table 1. Specific staining over the oocytes and the zonae pellucidae was seen on all of the sections examined. However, staining over the granulosa cells was observed in only 5 adult females; in these cases, cyclicity had not been verified and structural anomalies were observed that were not apparent in ovaries from cyclic females. Some oocytes appeared more condensed and surrounded with empty spaces and without any visible zona (Fig. 19). At higher magnification, the zonae appeared more diffuse than usual (Fig. 20). No fluorescence over the granulosa cells was noted for any of the cyclic females, regardless of the period in the cycle at which they had been killed. In addition, superovulation did not lead to any fluorescent staining on the granulosa cells.

\section{Zona material associated with granulosa cells in immature females}

All of the data that were recorded for immature females are summarized in Table 2 . The reactivity of the granulosa cells is presented as a function of age, hormonal treatment and the most advanced follicular development observed. The latter criterion reflects the effectiveness of the hormonal treatment. As observed in adult females, a positive reaction with the anti-zona serum was noted over the oocytes and zonae from every section examined but the reactivity of the granulosa cells was limited to 16 of the 41 females examined. These 16 females were between 23 and 29 days of age. A positive reaction on the granulosa cells of all of the observed follicles was noted in 3 females. For the other 13 positive females, granulosa cell reactivity was noted on some of the follicles while others were negative. In these females, the positive follicles showed an increased reactivity in the oocytes and fluorescence was often observed over the nuclei of the oocytes. In addition, the heterogeneous distribution of fluorescence which was previously seen over the zonae was no longer visualized (Fig. 21). In the follicles that did not show a fluorescent reaction in the granulosa cells, the zona and oocyte show a reaction which is identical to that of normal cyclic females (Fig. 22). A positive reaction of the granulosa cells was always associated with an abnormal ovarian histology (Fig. 23). PMSG treatment of 31-day-old females did not lead to such an abnormal ovarian histology (Fig. 24) or to any positive fluorescence in the granulosa cells. 
Table 2. Summary of the immunoreactivity on the granulosa cells during the normal or PMSG stimulated ovarian differentiation using anti-zona serum

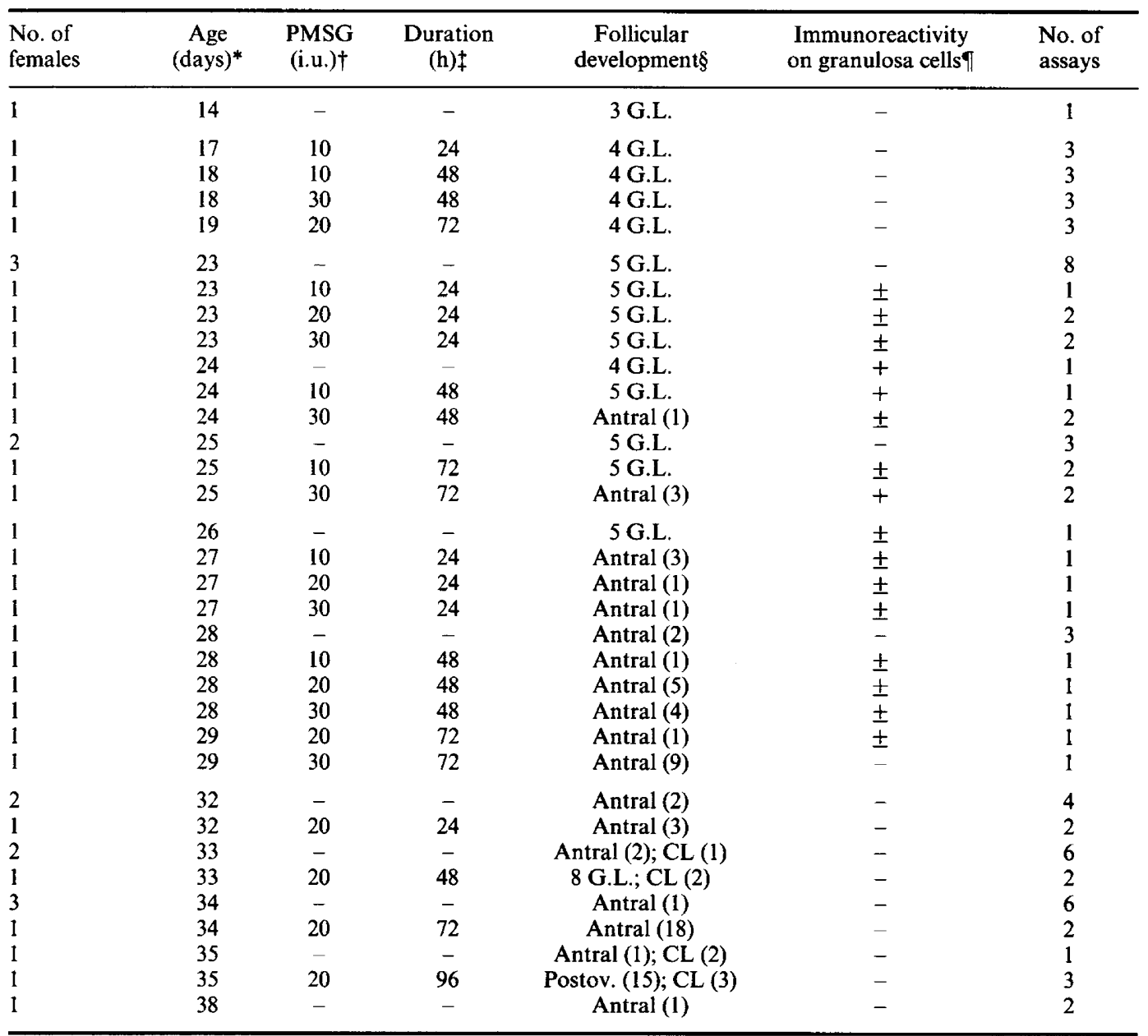

*Ages when the ovaries were excised; birth day = Day 1.

†PMSG was delivered as a single intraperitoneal injection.

†Interval between PMSG injection and excision of ovaries.

$\S$ Highest follicular development as described in Table 1 .

IFluorescence reactivity:-, all follicles were negative; + , all follicles were positive; \pm , some follicles were negative.

No specific staining was observed on extrafollicular ovarian cells or in any of the control tissues. Absorption of the anti-zona serum with red blood cells did not modify the specific staining observed on ovarian sections but adsorption on homogenized ovaries completely eliminated the specific staining.

\section{Discussion}

The use of oviducal rather than ovarian ova as the source of the immunogenic material prevents the contamination from granulosa cell remnants which may be present in ovarian zona preparations (Dunbar et al., 1980). Our antiserum appears to be specific towards zona glycoproteins since no interaction was observed with any of the control tissues (excluding the oviduct). 

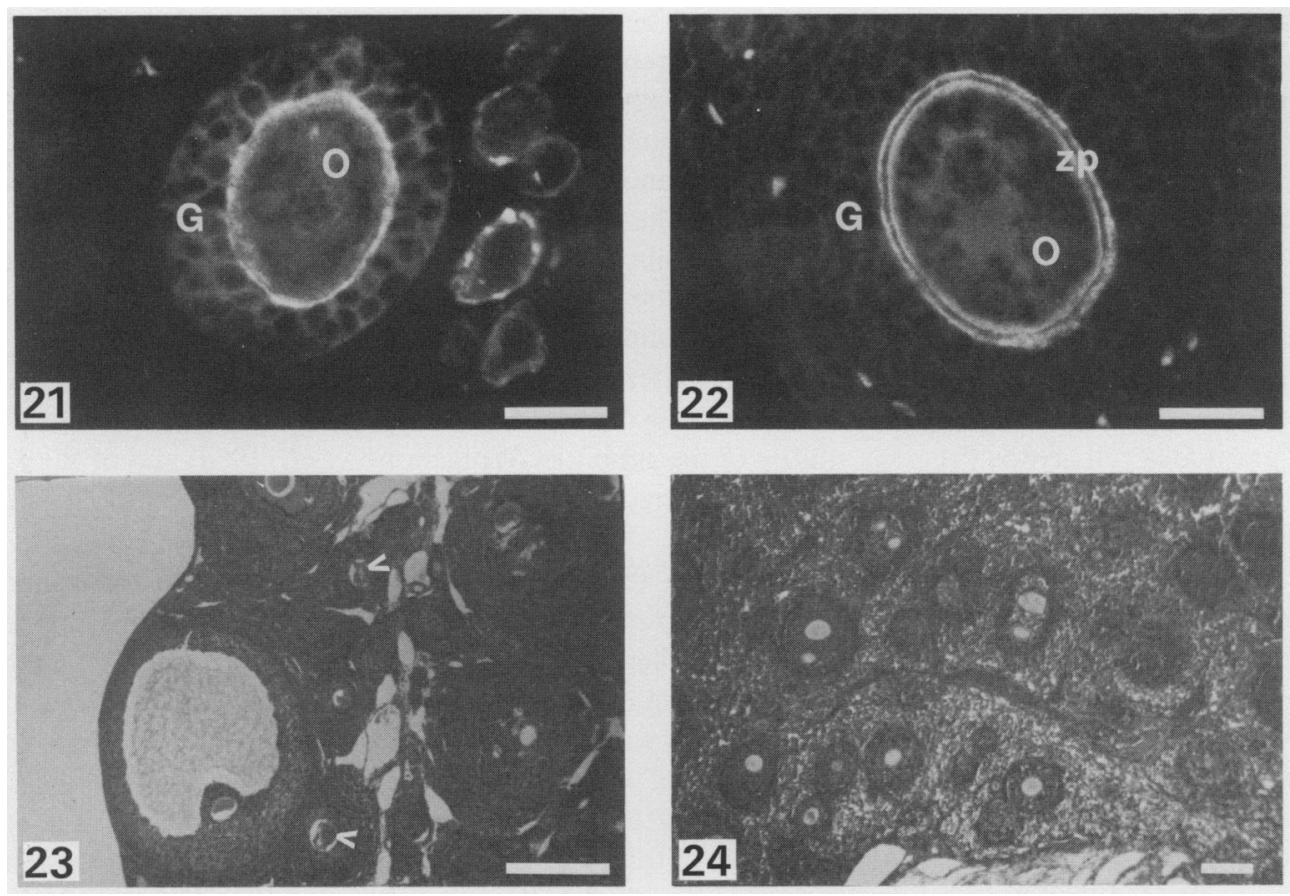

Figs 21-24. Immunoreactivity on the granulosa cells in sections of ovaries from PMSG (30 i.u. $24 \mathrm{~h}$ )-stimulated 27-day-old female hamsters. Figs 21 and 22: immunofluorescence using antizona serum of 2-cell layer (Fig. 21) and 4-cell layer (Fig. 22) follicle. Fig. 23: H.P.S. staining of an adjacent section; note the distorted oocytes (arrows). Fig. 24: H.P.S. staining on an ovarian section from a PMSG (20 i.u. 24 h)-stimulated 32-day-old female. G: granulosa; O: oocyte; zp: zona pellucida. Figs 21-23: bar $=30 \mu \mathrm{m}$; Fig. 24: bar $=100 \mu \mathrm{m}$.

The earliest age at which immunogenic zona components could be observed was in a 6-day-old female. In 1974, Challoner showed that the onset of meiotic prophase in female germ cells of the golden hamster occurs on the day of birth. By 5 days after brith, meiotic prophase was completed in $1.2 \%$ of the oocytes and by 7 days after birth, $79 \cdot 1 \%$ of the oocytes had reached this stage. Our results suggest that as soon as a sufficient number of germinal cells have ended meiotic prophase and a few of them have started to grow, the synthesis of zona material begins. It is not known whether the zona material influences the differentiation of granulosa cells from the squamous to the cuboidal shape which is one of the first steps in follicular development. This is possible since the presence of the oocyte is necessary for follicular organization to occur (Peters, 1978). Moreover, other types of extracellular matrix have previously been implicated in the process of cellular differentiation (Hay, 1981).

Immunogenic zona components have been observed in all of the oocytes. These include oocytes ranging in diameter from 20 to $68 \mu \mathrm{m}$ and enclosed in follicles in the primordial to the antral stages. This result would indicate that zona components are synthesized continuously during the entire growth phase of the oocyte. This result could also reflect the storage of zona components within the oocyte at certain stages of its growth. Studies in the mouse by Wassarman \& Bleil (1982) showed that oocytes of 35-62 $\mu \mathrm{m}$ are able to synthesize zona glycoproteins in vitro.

The gradual decrease in the immunoreactivity of the oocyte during its growth would indicate that a progressively decreasing portion of the metabolic activity of the growing oocyte is involved in the synthesis of the zona glycoproteins and that most of the zona glycoproteins are produced at a relatively early stage in oogenesis. This has been proposed by Shimizu et al. (1983) on the basis of 
in-vitro metabolic experiments with mouse ovarian follicles. Oocytes (45-55 $\mu \mathrm{m}$ diam.) synthesize only $0.4 \mathrm{pg}$ zona protein $/ \mathrm{h} /$ oocyte in vitro. Therefore, if a mouse zona contains $5 \mathrm{ng}$ protein, it would require about 520 days for each oocyte to synthesize its zona. Shimizu et al. (1983) therefore proposed that most of the zona proteins are probably produced earlier during oogenesis and at a much higher rate. A decreased intensity of immunoreaction on the oocyte could also be explained by a dilution effect due to the rapid increase in the size of the oocyte without any reduction in the rate of synthesis of zona material. This possibility is unlikely since Fléchon et al. (1984) have demonstrated that mouse zona material is not renewed after it is laid down around the oocyte and that zona synthesis stops about I week before resumption of meiotic maturation.

After secretion of the immunogenic zona material, a heterogeneity in its extracellular organization was observed. This uneven distribution was observed as early as follicular differentiation of two granulosa cell layers. Previous studies of the rabbit by Wolgemuth et al. (1984) and of the cow by Gwatkin et al. (1979) showed the same pattern of increased density of immunostaining at the inner and outer peripheries of the zona.

An immunoreactivity was also detected on the granulosa cells. In contrast to the staining observed on the oocytes, the staining of the granulosa cells occurred only at certain stages of follicular development, particularly at the earlier stages. In addition, only immature females, between 23 and 29 days of age exhibited staining on the granulosa cells. Some adult females also showed staining on the granulosa cells, but this was restricted to females for which no data were recorded concerning their cyclicity. This type of staining was not observed with cyclic females. Furthermore, granulosa cell staining was always found in ovaries showing an abnormal histology. Distorted oocytes, which in itself is diagnostic of follicular atresia (Byskov, 1979), and diffuse zonae have been noted in these ovaries. It is possible that this staining corresponds to the beginning of atresia in these follicles.

A similar type of staining of the granulosa cells in the mature rabbit has been reported by Wolgemuth et al. (1984). These authors detected an immunostaining only on those cells at the inner two layers of multiple-layer follicles and only at certain stages of follicular development. However, in this study, no information was provided concerning the hormonal status of these females. As discussed below, this is of critical importance in the interpretation of results showing immunoreactive zona material in granulosa cells.

We can make no suggestions as to why PMSG-treated immature females showed deviations in their ovarian development. The PMSG treatment, when administered to 16 or 31-day-old females, did not produce an abnormal ovarian histology nor positive fluorescence in the granulosa cells: 16-day-old females were unresponsive to PMSG whereas 31-day-old females responded like adult females.

Recent reports on immature hamsters showed that FSH binding is first detectable in the granulosa cells at Day 10 of age whereas LH binding to the interstitium first occurs on Day 15 (Shaha \& Greenwald, 1983). These ovarian events coincide with a significant increase in serum FSH and LH concentrations which, by Days 22-24 for FSH and by Days 19-21 for LH, reach values which are similar to those measured in prooestrous cyclic adult females (Bast \& Greenwald, 1974; Vomachka \& Greenwald, 1979). Previous studies on immature hamsters had shown that PMSG administration before the normal appearance of vesicular follicles (26-28 days old) results in a stimulation of the interstitium with little detectable effect on the follicular apparatus (Greenwald \& Peppler, 1968). These authors did not mention any follicular abnormality. However, it would appear that the ovary becomes functionally competent especially from Day 20 as judged from the increased amount of protein, cyclic AMP, gonadotrophin binding sites and a greater capacity to produce steroids (Shaha \& Greenwald, 1983). We suggest that, in the hamster, Day $20-26$ is a critical period at which the ovary evolves from a refractory to a receptive stage.

The present results demonstrate that the oocyte alone is responsible for the synthesis of the zona pellucida. They also provide an explanation for the conflicting results in the literature whereby the granulosa cells are often implicated in the actual synthesis of zona material. Immunoreactive zona 
material can be found in granulosa cells of abnormal follicles and represents a degradation of this material.

We thank the members of the Department of Pathology of Maisonneuve-Rosemont Hospital for their collaboration in the preparation of sections and Ms Jocelyne Laflamme for excellent secretarial assistance. This work was supported by a grant from the Medical Research Council of Canada.

\section{References}

Bast, J.D. \& Greenwald, G.S. (1974) Serum profiles of follicle-stimulating hormone, luteinizing hormone and prolactin during the estrous cycle of the hamster. Endocrinology 94, 1295-1299.

Bousquet, D., Léveillé, M.C., Roberts, K.D., Chapdelaine, A. \& Bleau G. (1981) The cellular origin of the zona pellucida antigen in the human and hamster. $J$. exp. Zool. 1215, 215-218.

Byskov, A.G. (1979) Atresia. In Ovarian Follicular Development and Function, pp. 41-57. Eds A. R. Midgley \& W. A Sadler. Raven Press, New York.

Challoner, S. (1974) Studies of oogenesis and follicular development in the golden hamster. 1. A quantitative study of meiotic prophase in vivo. J. Anat. 117, 373-383.

Chiquoine, A.D. (1960) The development of the zona pellucida of the mammalian ovum. Am. J. Anat. 106, 149-169.

Dudkiewicz, A.B. \& Williams, W.L. (1977) Fine structural observations of the mammalian zona pellucida by scanning electron microscopy. In Scanning Electron Microscopy, Vol. II, pp. 317-324. IIT Research Institute, Chicago.

Dunbar, B.S. (1983) Morphological, biochemical, and immunochemical characterization of the mammalian zona pellucida. In Mechanism and Control of Animal Fertilization, pp. 139-175. Ed. J. H. Hartmann. Academic Press Inc., New York.

Dunbar, B.S., Wardrip, N.J. \& Hedrick, J.L. (1980) Isolation, physicochemical properties, and macromolecular composition of zona pellucida from porcine oocytes. Biochemistry, N.Y. 19, 356-365.

Fléchon, J.E., Pavlok, A. \& Kopecny, V. (1984) Dynamics of zona pellucida formation by the mouse oocyte. An autoradiographic study. Biol. Cell 51, 403-406.

Greenwald, G.S. (1962) Analysis of superovulation in the adult hamster. Endocrinology 71, 378-389.

Greenwald, G.S. \& Peppler, R.D. (1968) Prepubertal and pubertal changes in the hamster ovary. Anat. Rec. 161, $447-458$.

Gwatkin, R.B.L., Meyenhofer, M. \& Williams, D.T. (1979) Localization of zona antigen in bovine ovary sections by fluorescent antibody. Gamete Res. 2, 201-206.

Haddad, A. \& Nagai, M.E.T. (1977) Radioautographic study of glycoprotein biosynthesis and renewal in the ovarian follicles of mice and the origin of the zona pellucida. Cell Tiss. Tes. 177, 347-369.

Hay, E.D. (1981) Collagen and embryonic development. In Cell Biology of Extracellular Matrix, pp. 379-409. Ed. E. D. Hay. Plenum Press, New York.

Kang, Y.H. (1974) Development of the zona pellucida in the rat oocyte. Am. J. Anat. 139, 535-566.

Mintz, B. (1962) Experimental study of the developing mammalian egg: Removal of the zona pellucida. Science, N.Y. 138, 594-595.

Modlinski, J.A. (1970) The role of the zona pellucida in the development of mouse eggs in vivo. J. Embryol. exp. Morph. 23, 539-547.

Pedersen, T. \& Peters H. (1968) Proposal for a classification of oocytes and follicles in the mouse ovary. $J$. Reprod. Fert. 17, 555-557.

Peters, H. (1978). Folliculogenesis in mammals. In The Vertebrate Ovary, pp. 121-144. Ed. R. E. Jones. Plenum Press, New York.

Petrusz, P., Ordonneau, P. \& Finley, J.C.W. (1980) Criteria of reliability for light microscopic immunocytochemical staining. Histochem. J. 12, 333-348.

Sacco, A.G. (1977) Antigenic cross-reactivity between human and pig zona pellucida. Biol. Reprod. 16, $164-173$.

Sacco, A.G. \& Shivers, C.A. (1973) Antigens of the rabbit ovary, oviduct and uterus. J. Reprod. Fert. 32, 403-414.

Shaha, C. \& Greenwald, G.S. (1983) Development of steroidogenic activity in the ovary of the prepubertal hamster. I. Response to in vivo or in vitro exposure to gonadotropins. Biol. Reprod. 28, 1231-1241.

Shimizu, S., Tsuji, M. \& Dean, J. (1983) In vitro biosynthesis of three sulfated glycoproteins of murine zonae pellucidae by oocytes grown in follicle culture. J. biol. Chem. 258, 5858-5863.

Tesoriero, J.V. (1984) Comparative cytochemistry of the developing ovarian follicles of the dog, rabbit, and mouse: origin of the zona pellucida. Gamete Res. 10, $301-318$.

Vomachka, A.J. \& Greenwald, G.S. (1979) The development of gonadotropin and steroid hormone patterns in male and female hamsters from birth to puberty. Endocrinology 105, 960-966.

Wasserman, P.M. \& Bleil, J.D. (1982) The role of zona pellucida glycoproteins as regulators of sperm-egg interactions in the mouse. In Cellular Recognition, pp. 845-863. Eds W. A. Frazier, L. Glaser, D. I. Gottlieb. Alan R. Liss, New York.

Wassarman, P.M., Greve, J.M., Perona, R.M., Roller, R.J. \& Salzmann G.S. (1984) How mouse eggs put on and take off their extracellular coat. In Molecular Biology of Development, pp. 213-225. Eds E. H. Davidson \& R. A. Firtel, Alan R. Liss, New York.

Wolgemuth, D.J., Celenza, J., Bundman, D.S. \& Dunbar B.S. (1984) Formation of the rabbit zona pellucida and its relationship to ovarian follicular development. Devl Biol. 106, 1-14.

Zamboni, L. \& Upadhyay, S. (1983) Germ cell differentiation in mouse adrenal gland. J. exp. Zool. 228, 173-194.

Received 12 May 1986 